\title{
The place of the psychiatrist in the new undergraduate medical curriculum*
}

\author{
Tom Sensky
}

\begin{abstract}
This paper summarises some of the key points ralsed at a workshop held in 1993 on the new undergraduate medical curiculum. At the workshop, the General Medical Councll's recommendations were summarised, and examples were presented of current undergraduate courses which met them. There was widespread support among workshop participants for psychiatists hoving an expanded role in the new curriculum, beyond a single clinical affachment, particularty in the teaching of communication skills and in collaborative teaching with other medical specialties.
\end{abstract}

The workshop was chaired by Professor Peter McGuffin. Speakers invited to give brief presentations were Professor Chris Thompson, Dr Jan Scott, Dr Phillip Snashall (Reader in Medicine and Assistant Dean for Medical Education, Charing Cross and Westminster Medical School), Dr Alison Birtle (Pre-Registration House Officer, Charing Cross Hospital), Dr Gabrielle Faire (Senior Registrar in Psychiatry, Basildon Hospital) and Professor David Shaw (Chairman of the General Medical Council Education Committee). Professor Arthur Crisp led the discussion.

The impetus for the workshop came from the recent interest among numerous UK medical schools in reforming their undergraduate medical curricula, in response to initiatives from the General Medical Council (GMC). The GMC's most recent recommendations have since been published (General Medical Council, 1993). Some of the key recommendations are summarised in Table 1. Participants were reminded that the GMC's interest in undergraduate medical education was not new, but that its earlier recommendations published in 1980 had not led to significant changes, except in a minority of medical courses. Numerous factors were possibly responsible for the difficulty in introducing the necessary changes. The traditional curriculum emphasised acquisition of facts, and led

*This was the title of a workshop held last year under the joint auspices of the Association of University Teachers of Psychiatry (AUTP) and the Royal College of Psychiatrists. medical students through a form of apprenticeship for clinical practice. Medical courses were traditionally built up in piecemeal fashion by giving different specialties and departments their own time in the course. As a result, each contributing department developed a vested interest in preserving its own input, while at the same time there was often no overview taken of the design of courses as a whole. An additional factor was the requirement, until the 1978 Medical Act, of medical schools to ensure the proficiency of their graduates in the practice of medicine, surgery and midwifery, at a time when postgraduate training was not obligatory.

\section{The modern undergraduate curriculum}

The main aim of the new undergraduate curriculum is to train students to the level required to achieve competence in their pre-registration house officer posts. This aim is more modest than used to apply for undergraduate training, because the increased importance of postgraduate education ensures that training continues beyond registration.

Some details were presented at the workshop of undergraduate curricula which had gone beyond the traditional model, notably at Southampton and Newcastle. Both these courses share several characteristics. In each, teaching is integrated across specialties (horizontal integration). This is facilitated by focusing teaching on systems and topics. Thus, for example, cardiology teaching involves collaboration between physiologists, pathologists and teachers of other disciplines as well as clinicians. Clinical and basic science aspects of a particular system are taught alongside each other. At the same time, there is also vertical integration, introducing clinical work early in the curriculum and also continuing teaching in basic sciences beyond the traditional 'preclinical' period. The courses emphasise the acquisition of appropriate 
Table 1. Summary of some of the key General Medical Council recommendations on the undergraduate medical curriculum

The burden of factual learning should be substantially reduced.

The undergraduate course should emphasise self-directed learning and equip the student with learning skills which will ensure that education continues throughout his/her professional career.

A core curriculum should be defined, encompassing essential knowledge and skills. and appropriate attitudes to be acquired during training.

The core curriculum should be system-based, with integration of teaching in clinical and basic sciences, thus eliminating the rigid preclinical-clinical divide and courses which are exclusively departmentally based.

The core curriculum should be augmented by a series of special study modules, allowing students to study in depth areas of particular interest to them.

The undergraduate course should equip the graduate with the essential skills required at the beginning of the pre-registration year.

The new curriculum should take full advantage of modern educational methods,

including the use of a wider range of technological resources.

Methods of assessment will need to be tailored to the new methods of teaching.

techniques for learning, such as self-directed learning and problem-solving, at the expense of the acquisition of increasing numbers of facts. At Southampton, the fourth year is given over to a single project, and the final year (as at Newcastle) includes a series of 'sub-intern' attachments, with little formal teaching.

Several participants stressed the difficulties involved in maintaining such effective integration. It has been a common experience that integration, even if successfully set up, does not maintain itself. At one medical school, it had been necessary to redesign the curriculum in 1988, because it had gradually slipped towards the 'traditional' model. At another, the integrated curriculum failed, probably because it required more teachers than were available. A pessimistic view was expressed about integrated teaching, suggesting that it will inevitably erode traditional methods.

Introducing new teaching methods also requires that teachers are taught to use these appropriately, and that adequate resources are available for innovations to succeed. It is also important to give teaching an appropriate prominent status among academics and clinicians. Introducing novel teaching methods inevitably requires the development of new methods of assessment appropriate to these.

\section{The place of psychiatry}

In keeping with the focus of the new curriculum on integration, there was no support among workshop participants for confining students' exposure to psychiatry within a single clinical attachment. The general consensus was that psychiatry should move away from the narrow focus, evident in many traditional undergraduate courses, on major psychiatric disorders to cover a wider range of topics which would be helpful to pre-registration house officers and others who would receive little if any further exposure to psychiatry during their postgraduate training. The inadequacies of current curricula in preparing house officers for dealing with the emotional aspects of illness were graphically illustrated by Dr Birtle, who described some of the problems she had had to face as a house officer, such as managing acute brain syndromes, and dealing with death or with distressed families. Some of the subspecialties in psychiatry (such as alcoholism and substance misuse) are also frequently encountered in clinical practice generally, and might warrant further exposure in the undergraduate course. The view was also expressed that, having worked for years to make behavioural sciences part of the undergraduate curriculum, it was important that their part in the new curriculum be safeguarded. Overall, discussion at the workshop acknowledged a greater role for the liaison psychiatrist in medical education.

Several examples were cited for psychiatrists collaborating effectively with others in their teaching. For example, at Newcastle, students learn about cases from the psychiatric and the primary care perspectives, and then have the opportunity to meet in small groups with a psychiatrist and general practitioner to discuss the cases further.

\section{The psychiatry core curriculum}

The new undergraduate medical courses are likely to comprise basic, essential features (the core curriculum) plus the opportunity to pursue elective options. One working example of this model, involving elective options, is the fourth year of the Southampton course, devoted to a single major project. In common with their 
colleagues in other specialties, psychiatrists will need to define the ingredients of the psychiatric core curriculum - the core aspects of psychiatry relevant to medical practice.

Numerous suggestions were made regarding components of this core curriculum. Requisite competencies include effective skills in communication and in the examination of the mental state, the ability to recognise, assess and initiate management of common psychiatric problems, and specific prescribing skills. Basic counselling skills were also noted in this context, although there was disagreement as to who was best able to offer training in these. Additional essential knowledge required includes (among other topics) factors associated with suicide risk and intent, causes of organic brain syndromes, the properties and uses of psychotropic drugs, and basic details of the Mental Health Act. Psychiatry should also foster appropriate attitudes among medical students, such as the empathic understanding of emotional problems, the acknowledgement that psychiatric problems are commonly stigmatising, an emphasis on a holistic approach to medicine, and an appreciation of the clinician's role working in multidisciplinary and multiprofessional teams.

\section{Contributions of psychiatry outside the core curriculum}

Attention at the workshop was drawn to other areas of the psychiatrist's expertise. It was pointed out that, among the medical specialties, psychiatrists had more experience than most in working with other professionals, and in crossing the boundary between hospital and community. They should thus consider taking the lead in demonstrating these aspects of practice to the students. It was suggested that the focus of teaching about schizophrenia could shift away from the disorder itself, to more general principles such as multidisciplinary teamwork.

One of the questions discussed most thoroughly at the workshop was the role of the psychiatrists in training in communication skills, which have (appropriately) received greater emphasis in the new curriculum. Nonpsychiatrists commonly perceived psychiatry as offering skills and expertise in communication skills, and one view at the workshop was that psychiatrists should actively pursue their involvement in this aspect of clinical training. One example was cited of an undergraduate course in which psychiatrists were unilaterally given more responsibility for communication skills training, without prior consultation with the psychiatrists themselves. Other participants cautioned against this view, that psychiatrists should adopt communication skills training as their own. It was pointed out that within psychiatry itself, formal training in communication skills, although increasing, is not universal. Also, all clinicians should have effective communication skills, and training should therefore involve a wider range of clinical specialists than psychiatrists and general practitioners, although these latter might take the lead for the present.

\section{Further directions}

The workshop offered participants the opportunity to share and discuss some innovative ideas, and to learn of instances where such ideas had already been applied. In discussions at the end of the meeting, two specific topics were identified as potentially worthwhile to pursue further - the development of a model core curriculum for psychiatry, and the devising of some means whereby innovative teaching and training methods might be disseminated. At its most recent meeting, the AUTP Executive agreed to take forward the first of these proposals. As a start, a survey is being undertaken of all undergraduate courses, aiming to identify those which have already developed a core psychiatry curriculum, and bringing together information from the curricula already avallable.

\section{Reference}

General Medical Council (1993) Tomorrow's Doctors: recommendations on undergraduate Medical Education. London: GMC

Tom Sensky, Senior Lecturer in Psychiatry, Charing Cross and Westminster Medical School, West Middlesex University Hospital, Isleworth, Middlesex TW7 6AF 